\title{
ESTÉTICA, MARXISMO E EDUCAÇÃO: UM DIÁLOGO NECESSÁRIO À CONTEMPORANEIDADE
}

Karla Raphaella Costa Pereira ${ }^{1}$ Frederico Jorge Ferreira Costa ${ }^{2}$

\begin{abstract}
Resumo
O presente artigo é resultado de pesquisa em Pós-graduação em Educação e objetiva contribuir para os debates contemporâneos sobre estética, literatura e educação. Toma como fundamento teórico o método de Marx que pousa o homem no centro da história, demonstrando que os objetos, inclusive os objetos espirituais, foram colocados na realidade pela ação consciente do homem, ou seja, pelo trabalho, bem como na teoria estética e literária lukacsiana. Discute a importância dessas teorias para os estudos contemporâneos acerca do papel da arte e da literatura, destacando como o professor de literatura pode ter sua práxis enriquecida por este conhecimento. Foi uma pesquisa bibliográfica de compreensão categorial para colaborar teoricamente com o trabalho do professor de literatura. Advoga uma práxis no ensino de literatura que considere a obra literária e seu caráter educativo diante do mundo dos homens.
\end{abstract}

Palavras-chave: Estética. Marxismo. Educação.

\section{AESTHETICS, MARXISM AND EDUCATION: A NECESSARY DIALOGUE ON CONTEMPORANEITY}

\begin{abstract}
This article is the result of research in Postgraduate Education and aims to contribute to contemporary debates on aesthetics, literature and education. It takes as theoretical basis the method of Marx that puts the man at the center of history, demonstrating that objects, including spiritual objects were placed in reality by the conscious action of man, that is, the work, as well as in aesthetic theory and literary Lukacsian. Discusses the importance of these theories to contemporary studies on the role of art and literature, highlighting how the literature teacher can have their practice enriched by this knowledge. It was a bibliographic research of categorical understanding to theoretically work with the literature teacher's work. Advocates practice in the teaching of literature to consider the literary work and its educational character to the world of men.
\end{abstract}

Keywords: Aesthetics. Marxism. Education. 


\section{INTRODUÇÃO}

O estudo da estética no marxismo tem conquistado espaço nos últimos anos devido, em grande medida, às publicações e à difusão do pensamento de György Lukács, filósofo húngaro que dedicou parte de sua carreira intelectual ao resgate dos fundamentos do marxismo e à recolocação do entendimento do processo de autocriação humana por meio do trabalho.

György Lukács nasceu em Budapeste em 13 de abril de 1885. Filho de dirigente de grandes estabelecimentos bancários, Lukács teve uma educação burguesa. Iniciou sua carreira intelectual ainda muito jovem; com 17 anos, publicou seus primeiros artigos na imprensa húngara. Faleceu aos 86 anos, ainda produzindo aquilo que seria o legado de sua vida: a refundação do marxismo pelo resgate ontológico das raízes da obra marxiana. Segundo José Paulo Netto (1992), a mais original contribuição de Lukács deu-se no nível estético, campo historicamente carente de uma análise mais sistematizada no marxismo.

O presente artigo é fruto de pesquisa de mestrado no âmbito da educação e objetiva contribuir com o debate sobre a importância da arte e da estética na formação humana, tomando a teoria lukacsiana como ponto de partida. O referencial teórico marxista tem a função de qualificar o debate acerca das superestruturas como momentos da materialidade do real, entendendo que os complexos ideológicos expressam a realidade exterior e independente do homem.

Lukács é conhecido e discutido hoje principalmente por sua obra Para uma ontologia do ser social publicada em 1973, dois anos depois de sua morte. Nessa obra, desdobra uma ontologia pautada em Marx que se diferencia das ontologias idealistas por não ser especulativa. (COSTA, 2007). Noutras palavras, o autor parte das conquistas históricas, como fez o próprio Marx, para explicar o fundamento do mundo dos homens por ele mesmo e pela natureza. Além disso, Lukács aponta os limites de alguns teóricos da tradição filosófica que também procuraram explicar a realidade, destacando, ao mesmo tempo, aqueles que contribuíram para a construção da teoria marxista.

A Estética, publicada em 1963, é, entretanto, tão importante quanto Para uma ontologia do ser social. Aquela Lukács publicou ainda em vida, pôde revisar e dar o formato que desejava. É possível afirmar que a Estética possui um conteúdo tão ontológico quanto o da Ontologia, apesar de seu autor não reivindicar o termo para si e para a referida obra. Nela, Lukács apresentou o desenvolvimento histórico de complexos e categorias do real de modo genético, como ele mesmo denomina, a exemplo da arte, da ciência e da religião, descrevendo o reflexo, a analogia, a mimese, dentre outros.

$\mathrm{Na}$ Estética e em artigos paralelos o filósofo húngaro executa estudos de teoria e crítica literária. Nesses textos fica claro o fundamento marxiano do raciocínio de Lukács a respeito da arte e da literatura e sua contribuição à contemporaneidade. A compreensão da realidade como uma totalidade de complexos permite entender as relações dialéticas do mundo dos homens, como também a relação entre estética, literatura e educação.

Apresenta-se aqui, nos limites permitidos por um artigo, o teórico e sua teoria, bem como seus estudos acerca dos filósofos que se dedicaram à questão estética, como Kant, Herder, Scheller, Schelling, Solger e Hegel, sob a análise de Lukács; até a elaboração do materialismo histórico-dialético de Marx e Engels. Leandro Konder, Carlos Nelson 
Coutinho, José Paulo Netto, Celso Frederico, Miguel Vedda, Nicolas Tertulian e Antonino Infranca são alguns dos autores aqui indicados dada a importância deles no campo do marxismo, de forma geral, e no da estética, em particular. Konder, Coutinho e Paulo Netto têm o mérito de serem os primeiros grandes estudiosos brasileiros a se debruçar sobre o legado lukacsiano no Brasil, publicando obras e interpretações seminais de Lukács.

\section{LUKÁCS E A EXISTÊNCIA DE FUNDAMENTOS ESTÉTICOS PRESENTES NA OBRA MARX E ENGELS}

O interesse de Lukács pelas questões de arte e estética não se originou na maturidade. Apesar de uma importante ruptura ocorrer em seu pensamento nos anos 1930, a consolidação madura de sua teoria estética é resultado de uma evolução intelectual iniciada na saída da adolescência quando produz seus primeiros ensaios.

Com 26 anos, Lukács publica História do desenvolvimento do drama moderno com o qual é premiado em 1908. Uma obra, segundo Coutinho e Paulo Netto (2011, p. 08), impregnada de neokantismo com preocupações sociológicas filtradas pelas lentes de Georg Simmel. Entre 1908 e 1910, escreve uma série de artigos publicados em 1911, como a coletânea A alma e as formas, fase que ele mesmo denominaria de anticapitalismo romântico, devido às indagações existencialistas e à falta de uma perspectiva centrada na realidade.

De acordo com Coutinho e Paulo Netto (2011, p. 8-9), entre 1912 e 1917, produz alguns estudos sobre Dostoiévski e deixa algumas obras inacabadas. Considerada pelos intérpretes acima citados a fase de mais tensa conexão entre estética e ética, manifestada principalmente no fascínio por Dostoiévski como o representante da saída da crise aguda e sem esperanças deste período. Fase, ainda, predominantemente neokantiana e, posteriormente, renegada. "O Lukács influenciado por Dostoiévski é o Lukács que postula duas éticas contrapostas: a primeira ética (a do dever para o Estado) e a segunda (a ética da alma)". (INFRANCA, 2006, p. 18, tradução nossa).

Há consenso entre os estudiosos de Lukács, a exemplo de Tertulian (2008), Coutinho e Paulo Netto (2011), de que a obra A teoria do romance, que seria uma introdução ao estudo de Dostoiévski e se tornou autônoma, representa uma primeira clara ruptura, um avanço em relação ao pensamento anterior de Lukács por estar muito mais próxima a uma compreensão dialética da história. Nessa obra ocorre a passagem de Lukács do idealismo subjetivo de Kant para o idealismo histórico-objetivo de Hegel. Há nela uma intensa preocupação em vincular arte e sociedade, objeto do futuro marxista, mas aqui ainda em gestação.

Em 1918, Lukács adere ao marxismo, assumindo encargos políticos e participando ativamente do curto governo proletário na Hungria. Escreve História e consciência de classe, obra das mais célebres até hoje, apesar de insistentemente Lukács provocar o debate no caminho de sua superação; além de republicar vários ensaios na coletânea Tática e ética. Entre 1919 e 1930, não se ocupa predominantemente das questões estéticas, mas das políticas.

Em 1930-1931, trabalhando no Instituto Marx-Engels de Moscou com o pesquisador soviético Mikhail Lifschitz, analisa os originais dos Manuscritos econômico-filosóficos de 
Marx e dos Cadernos filosóficos de Lenin. Lifschitz e Lukács sustentaram, com base nos estudos dos originais dos clássicos do marxismo, que há uma estética em Marx e Engels. Essa tese sempre enfrentou oposição, pois os debates pós-1917 giravam, segundo Lukács (2011, p. 25), em torno de problemas políticos, estratégicos e táticos, por isso os discursos dominantes sobre a estética eram os de Plekhanov e Mehring para os quais a estética não era parte integrante do sistema marxista.

Mikhail Lifschitz (2010) apresenta alguns fatos para explicar a negação e/ou dificuldade de reconhecimento de uma estética marxista. Dentre eles, o declínio do nível geral da literatura marxista, depois da morte de seus fundadores, no período da Segunda Internacional, pois seus dirigentes, como é sabido, deformaram a teoria marxista no campo da política, da economia e da filosofia, configurando um retrocesso do entendimento da materialismo histórico.

Outro motivo apontado por Lifschitz: durante muito tempo a literatura burguesa recusou-se a aceitar Marx como um filósofo, pois ele não havia deixado um tratado sistematizado de filosofia. Com base no mesmo argumento, uma estética marxiana não era considerada existente. As partes das obras em que Marx e Engels tratavam de arte e literatura eram tomadas como segundo plano, como fundamentação para a teoria do materialismo histórico. "Por isso, permaneceram ignoradas as ideias de Marx e Engels sobre a arte, ricas em conteúdo ideológico, estreitamente vinculadas à teoria do conhecimento e à concepção histórico-universal do marxismo". (LIFSCHITZ, 2010, p. 45).

A defesa de uma estética marxista feita por Lifschitz e Lukács passa pela compreensão materialista histórico-dialética do mundo dos homens, está intrinsecamente relacionada à análise marxiana da história e somente pôde ser esboçada após a correta apreensão, por parte de Lukács, do marxismo.

As questões relativas à arte, como de quaisquer complexos sociais, de sua função e influência na história constituem o "[...] processo social geral e unitário através do qual o homem se apropria do mundo através de sua consciência". (LUKÁCS, 2010b, p. 13). A teoria marxiana traçou o entendimento da história dos homens como resultado de sua própria atividade, inclusas todas as objetivações produzidas.

Do primeiro ponto de vista, a estética marxista e a história marxista da literatura e da arte fazem parte do materialismo histórico, ao passo que, do segundo ponto de vista, são uma aplicação do materialismo dialético; em ambos os casos, porém, são uma parte peculiar, especial, deste conjunto, com determinados princípios estéticos específicos. (LUKÁCS, 2010b, p. 13).

A ideia central do marxismo, que Lukács sustentou e desenvolveu, é a de que o homem se faz homem mediante o resultado de seu próprio trabalho, como dito anteriormente. A consequência disso para a estética e a arte é a de que as atividades espirituais humanas são resultado desse processo, não de uma força ou ideia transcendente à realidade humana. Não são, entretanto, um resultado unívoco do trabalho, mas se desenvolveram na história, com relativa autonomia perante ele.

Em resumo, segundo Lukács (2010b): a) existem muitos fragmentos nas obras de Marx e Engels sobre arte e literatura que formam um todo articulado, dada a organicidade 
de seu pensamento; b) o método marxiano, fiel à realidade objetiva, coloca o estudo da arte e da estética no plano dessa realidade.

"Foi com base nesta possibilidade de construir os fundamentos de uma estética marxista sistemática que Lukács retomou suas preocupações com temas especificamente artísticos e literários". (COUTINHO; PAULO NETTO, 2011, p. 10). Na maturidade, o estudo de Lukács volta-se para o resgate do fundamento ontológico do marxismo e para a restauração de suas bases. As duas principais obras deste período são a Estética e a Ontologia do ser social. Cronologicamente, a Estética vem primeiro, mas, do ponto de vista do desenvolvimento da exposição dos fundamentos, a reflexão ontológica de Lukács guarda esse lugar, sendo o fundamento da Estética.

Após essa breve apresentação da biografia intelectual de Lukács, é interessante aludir a não linearidade de sua trajetória intelectual. Existem estudiosos de Lukács que se colocam em determinadas fases do desenvolvimento de sua teoria e não assumem que o filósofo renegou algumas concepções anteriores. Ao contrário, parte-se aqui da compreensão dessa trajetória como resultado de um passado com o qual o autor não rompe drasticamente, nesse sentido procura-se compreender as particularidades do caminho percorrido, suas permanências, rupturas e superações.

\section{CONTRIBUIÇÕES DE LUKÁCS PARA A HISTÓRIA DA ESTÉTICA}

Para Lukács (2011, p. 43-45), as tentativas de criar uma história da arte e da literatura anteriores à filosofia clássica alemã eram, em geral, de natureza empírica. Nos casos em que houve a tentativa de erigir uma fundamentação filosófica, ela foi abstrata, não permitindo a correta compreensão das leis da arte e da história.

Em fins do século XVII e inícios do século XVIII, a querela entre antigos e modernos sobre a nascente literatura e a nova arte ganhou, de acordo com Lukács (2011, p. 44), contornos mais radicais. A ideologia revolucionária burguesa expressou-se como uma defesa da arte autêntica contra a falsa arte.

Decerto, no curso do empenho do iluminismo para justificar teoricamente a nova arte, surgem pontos de vista históricos na concepção da literatura e da arte. Rousseau já percebe muito nitidamente a problemática e a contraditoriedade da cultura (em especial, da arte). Entretanto, nem mesmo os intentos mais amplos e significativos no campo da estética favoreceram uma compreensão sistemática da história e das suas leis. (LUKÁCS, 2011, p. 44).

Lukács (2011, p. 44) conclui que o pessimismo de Rousseau fomentou a subestimação da arte em geral e que Herder, filósofo alemão influenciado por Kant, não conseguiu articular o materialismo espontâneo de suas interpretações históricas com uma concepção materialista da própria arte. Desta forma, o iluminismo não conseguiu resolver o problema da conexão entre a história e a teoria; solução que só será alcançada na filosofia clássica alemã.

Em suas Teses sobre Feuerbach, Marx aponta precisamente o aspecto metodológico que contribuiu para essa inflexão. Ele sublinha que, em todas as 
antigas teorias materialistas, tem lugar uma deficiente apreensão do mundo, que é tomado só a partir da contemplação e não da práxis; ou seja, tais teorias descuram o aspecto subjetivo da atividade humana. (LUKÁCS, 2011, p. 45).

Marx afirma que o aspecto ativo foi desenvolvido abstratamente pelo idealismo que não conhece a atividade real e sensível como tal. (MARX; ENGELS, 2007). Kant coloca a atividade do sujeito estético, em seu comportamento produtivo e em seu comportamento receptivo, no centro de seu método e sistema. De acordo com Lukács (2011, p. 45), a Crítica da faculdade de julgar, por se ater a esse aspecto ativo, reorienta a história da estética. Nesse sentido, Kant é considerado como o iniciador do processo que culminará na elaboração marxiana, ou seja, há alguns avanços em suas teorizações em meio aos equívocos.

Como idealista subjetivo e limitado pela teoria do conhecimento de sua época, Kant possui limitações intransponíveis: ele nega a teoria estética do reflexo, por isso só consegue determinar o objeto estético de modo puramente formalista e as questões de conteúdo são colocadas fora do campo estético. Em Kant "[...] desaparece quase completamente em sua estética o papel histórico e social da arte". (LUKÁCS, 2011, p. 45).

$\mathrm{Na}$ análise de Lukács (2011), Schiller foi o primeiro grande seguidor do método kantiano, um pensador de transição entre o idealismo subjetivo e o idealismo objetivo. Apesar de se empenhar na construção de um idealismo objetivo ainda se mantinha preso, no que tange à teoria do conhecimento, a Kant. Caminhou, entretanto, no sentido de superar o estilo a-histórico da estética de seu mestre. Em Schiller, a análise da atividade do sujeito estético é um problema histórico; ele percebe a conexão das categorias subjetivas, sobre as quais ainda opera, com as transformações históricas e sociais.

Quem já consuma a transição para o idealismo objetivo é Schelling que publica em 1805 sua primeira estética sistemática. O filósofo tenta apresentar a dialética como força motriz da realidade objetiva, retoma a teoria do reflexo, mas de modo inteiramente mistificado, como uma renovação da teoria platônica das ideias. Lukács, por isso, avalia que ele, na verdade, oscila entre idealismo e materialismo.

\footnotetext{
Em sua estética, há uma tendência a deduzir as questões mais importantes da evolução histórica da arte da dialética objetiva da realidade; contudo, em sua realização efetiva, ao lado de muitas observações analíticas percucientes, a dialética de Schelling termina por se mover, graças à sua própria essência, entre analogias abstratas e a imersão num misticismo irracional. (2011, p. 47).
}

A limitação de Schelling se apresenta, para Lukács (2011, p. 48), no fato de que a passagem do pensamento mecanicista ao dialético ocorra por via intuitiva. Já em Solger, filósofo romântico alemão, o movimento dialético é muito mais vivo do que em Schelling, mas ele não consegue unificar este movimento numa síntese dialética.

Hegel foi fundamental para Marx e o desenvolvimento de seus estudos. No campo da estética, essa importância é bastante viva, por isso, Lukács foi um defensor de que estudar com profundidade a teoria hegeliana era de fundamental importância para a correta compreensão do marxismo. Não é diferente no campo da estética.

A estética de Hegel representa, no campo da filosofia da arte, a culminação do pensamento burguês, das tradições burguesas progressistas. Os conhecidos aspectos positivos do pensamento de Hegel e do seu estilo têm a sua mais clara 


\begin{abstract}
expressão nesta obra: o seu caráter de universalidade, a sua profunda e aguda sensibilidade em face das peculiaridades e contradições do processo histórico, a vinculação dialética dos problemas históricos com as questões teóricas e sistemáticas referentes às leis objetivas universais - todos estes traços positivos da filosofia hegeliana se expressam nitidamente na estética. Os clássicos do marxismo apreciaram muito esta obra. (LUKÁCS, 2011, p. 43).
\end{abstract}

Lukács (2011, p. 53) assevera que Hegel luta, como idealista objetivo, pelo reconhecimento da verdade objetiva absoluta das categorias estéticas; como dialético vincula esta essência ao caráter histórico, ou seja, procura sempre apreender o entrelaçamento entre o absoluto e o relativo. O todo da estética é uma parte do desenvolvimento histórico do mundo no caminho ao espírito Absoluto. Os graus de manifestação do Espírito são, em Hegel, a intuição, referente à estética; a representação, da religião e o conceito, da filosofia. Este é o caminho para o Absoluto.

Hegel supera o idealismo subjetivo de Kant porque parte sempre do conteúdo. As categorias estéticas fundamentais, como a Beleza, o Ideal, etc., são deduzidas da análise histórica concreta. O conteúdo, no entanto, é o estado do mundo, o estado de desenvolvimento da sociedade e da história. "O idealismo hegeliano é um idealismo objetivo que pretende reconhecer a realidade objetiva como independente da consciência humana e expressá-la filosoficamente numa forma dialeticamente racional". (LUKÁCS, 2011, p. $57-$ 58).

Mas, como aponta Lukács (2011), o conceito de objetividade de Hegel é idealista “[...] é uma objetividade de natureza espiritual, mental”. (LUKÁCS, 2011, p. 58). Na verdade, o Espírito do Mundo, que existe independentemente da consciência subjetiva humana e até criadora dela, seria o objetivo a ser alcançado, ou seja, seria a dissolução de toda objetividade. Os avanços de Hegel, seu entendimento de que o conteúdo concreto determina a forma estética concreta, estabelecem uma percepção sempre histórica do conteúdo, este seria o grande mérito da estética de Hegel: a tentativa de historicizar as categorias estéticas. Lukács $(2011$, p. 65) reafirma que a estética hegeliana põe de fato o "[...] fundamento para uma estética científica, indissoluvelmente teórica e histórica".

Este tópico, sob a perspectiva de Lukács, pôs em relevo as elaborações de filósofos anteriores a Marx para fundamentar a argumentação de que a concepção materialista histórico-dialética de Marx colocará no centro do debate a radical historicidade de todas as categorias estéticas. Marx finca estacas na assertiva de que a arte é um produto humano.

\title{
ARTE, ESTÉTICA E SOCIEDADE NA PERSPECTIVA DO MARXISMO DE LUKÁCS
}

Para o marxismo, nenhuma categoria humana existe a priori, todas são resultados do processo unitário da história. Desta forma, a arte e a estética não possuem uma história autônoma, resultado de sua dialética imanente, ao contrário, Marx e Engels demonstraram que os seres humanos, mediante seu trabalho, afastaram-se das barreiras naturais e puderam construir um mundo humano, no qual todas as categorias são resultado de sua intervenção na natureza e de sua história. Sobre isso, Marx (2010) afirma que a riqueza da sensibilidade 
subjetiva humana só pode ser em parte criada e em parte aperfeiçoada pela riqueza objetivamente explicitada da essência humana.

Os sentidos que captam as experiências para o desfrute humano, que colhem a beleza da arte para a fruição do homem são resultado da atividade do sujeito. Marx (2010) esclarece que a diferença entre os sentidos humanos e os sentidos animais é social, que foram construídos socialmente pelo próprio homem e, assim, foram se diferenciando da determinação biológica da esfera do ser natural.

Sobre isso, Lukács (1982), na Estética, atenta para o fato de que o olho da águia, por exemplo, é capaz de captar muito mais detalhes dos objetos e distâncias muito maiores do que o olho humano; é biologicamente mais potente, entretanto, não é capaz de perceber nuances que somente o olho humano capta. Isso se dá pelo fato de que essas nuances imperceptíveis para a águia são sociais. A história dos cinco sentidos humanos é, como argumenta Marx (2010), a história da riqueza do mundo criado pelo homem.

\begin{abstract}
A gênese histórica da arte, em sentido produtivo e no da receptividade artística, tem que ser tratada no marco da gênese dos cinco sentidos, que é o marco da história universal. O princípio estético se apresenta assim como resultado da evolução histórico-social da humanidade. (LUKÁCS, 1982, p. 240, tradução nossa).
\end{abstract}

Marx (2010) expõe que todas as capacidades humanas e seus objetos tiveram uma origem paulatina, radicalmente histórica. Os objetos existem fora da consciência humana, mas é necessário que haja uma atividade transformadora para que esses objetos ganhem um sentido para o sujeito. Os objetos artísticos só são objeto para um sujeito e este sujeito se fez no processo histórico.

Não se pode, então, explicar a arte como uma capacidade humana original ou inata. Hoje, como objetivação superior, a arte pode parecer um objeto apartado da atividade humana, inclusive, graças à divisão capitalista do trabalho, mas trata-se de pura aparência. Lukács refuta justamente essa falsa compreensão.

\footnotetext{
Para o idealismo ocorre como se o princípio estético unitário, "originário" (apriorístico), se diferenciasse conceitualmente e se sistematizasse num sistema de artes, enquanto que na realidade nascem, de relações qualitativamente diversas com a mesma, baseadas na unidade objetiva desta e na diversidade qualitativa dos órgãos receptivos e seu desenvolvimento histórico-social, diversas atividades, objetividades, receptividades, etc., artísticas. (LUKÁCS, 1982, p. 241, tradução nossa)
}

O materialismo histórico-dialético procura romper com as concepções que defendem a origem das artes particulares a partir da essência do homem, bem como da completa separação entre elas. Ao contrário, tenta apontar que há uma multiplicidade de origens reais e que há uma unidade no estético que é resultado de uma evolução histórico-social.

Assim, Lukács (1982) não busca o sentido eterno ou o momento exato do nascimento das artes, mas o período com o menor número de objetivações na história humana, isto é, a gênese. Pois, é esse movimento em direção a gênese que permite acessar o fio condutor do processo evolutivo das artes. Segundo ele, a atividade artística supõe certo desenvolvimento material, certo avanço das técnicas e um ócio para a criação. A objetivação artística, portanto, 
não é contemporânea do trabalho, ou seja, não nasceu junto com ele, mas tem sua gênese mais tardia. Para fazer arte o homem já tinha se desenvolvido socialmente em alguma medida.

A distinção entre trabalho e arte não é simples e somente pode aparecer nas objetivações mesmas, não em seus reflexos conscientes. Segundo Lukács (1982), retomando Marx, a diferença decorre da relação com a utilidade imediata. Nos estados primitivos os objetos tinham uma utilidade prática imediata, o adorno humano, por exemplo. $\mathrm{O}$ desprendimento do reflexo desantropomorfizador ${ }^{3}$, o avanço do conhecimento, da ciência, da história, introduz utilidades mediadas e os elementos estéticos podem ter representado um excesso que foi ganhando novas significações. "A gênese do estético é um análogo desprender-se da autoconsciência em relação à prática cotidiana, como a gênese da 'consciência de' na ação de tornar-se independente do reflexo científico da realidade". (LUKÁCS, 1982, p. 253, tradução nossa).

O objeto fundamental do reflexo estético é a sociedade e seu intercâmbio com a natureza. Essa forma de reflexo antropomorfizador cria formas específicas da realidade que nascem dela e retornam a ela. Assim, a arte cria um mundo homogêneo que lhe permite elaborar uma "[...] autoconsciência do desenvolvimento da humanidade". (COUTINHO; PAULO NETTO, 2011, p. 15, grifo do autor). A arte é uma forma específica do reflexo da realidade exterior à consciência do homem, é, portanto, um tipo de conhecimento de si mesmo do homem.

Segundo Infranca (2006), a categoria essencial que Lukács desenvolverá em sua fase de maturidade é a da generidade [Gattungsmäßigkeit], percebida no Marx dos manuscritos. Assim, Infranca (2006, p. 23, tradução nossa) explica: “[...] um homem é um homem em todas as circunstâncias, em cada um dos seus gestos e em cada momento de sua existência". A estética é, no pensamento de Lukács, uma manifestação do ser genérico do homem, não um epifenômeno.

A estética marxista, segundo Lukács (2010b), ao contrário do que afirmam seus detratores, realça o papel criador do sujeito, pois, na relação entre essência e fenômeno, apenas um esforço sério no sentido de superar a aparência pode revelar um conhecimento verdadeiro da história humana. Apenas os grandes artistas são capazes de se debruçar no esforço de construir, através da arte, um conhecimento verdadeiro da realidade.

\section{ENSINO DE LITERATURA: ELEMENTOS PARA UM DEBATE SOBRE OESTÉTICO E A FORMAÇÃO HUMANA}

O ensino é um momento essencial da educação formal. Pode-se afirmar categoricamente que não há sociedade humana sem o complexo da educação. Na dinâmica da reprodução social existe uma mediação responsável pela apropriação, por parte dos indivíduos concretos, do que é produzido historicamente e socialmente pela humanidade. Essa mediação, em sentido amplo é a educação. No capitalismo se objetiva na escola, que torna-se um dos mecanismos centrais no processo de formação humana por meio do ensino.

No caso em questão, centra-se na importância do ensino da literatura como mecanismo de formação humana para uma sociabilidade emancipada, que pressupõe a 
democratização do acesso à educação dos sentidos, na escola pública, para milhões de filhos de trabalhadores.

De acordo com Lukács (2010a, p. 30a), o objetivo da literatura, assim como o da arte, de modo geral, é proporcionar uma imagem, ou seja, um reflexo da realidade objetiva na consciência do homem que evidencie uma imediatez unitária na qual essência e fenômeno coincidam. $\mathrm{O}$ autor quer dizer que, na literatura e na arte, a representação do mundo exterior permite uma melhor compreensão de aspectos ali destacados devido à homogeneidade do mundo da arte, diferentemente do cotidiano que é um mundo heterogêneo.

Dois pares de categorias são fundamentais para o entendimento do que afirma Lukács: totalidade extensiva - totalidade intensiva e homem inteiro - homem inteiramente. A totalidade extensiva corresponde, justamente, ao que ele explica sobre a heterogeneidade da realidade, a complexidade da totalidade social e dos vários complexos sociais que se interrelacionam. A ciência, com seu reflexo desantropomorfizador, procura entender, extensiva e progressivamente a totalidade da realidade, já a arte preocupa-se com a criação de um mundo homogêneo em seu reflexo antropomorfizador.

A totalidade representada na arte, em conexão com a extensiva, intensifica em seu reflexo um aspecto da realidade. Dessa forma, é possível ao homem debruçar-se inteiramente sobre o aspecto da realidade ali representado. $\mathrm{O}$ homem imerso no cotidiano heterogêneo da realidade é um homem inteiro, segundo Lukács, porque em sua inteireza está voltado para o cotidiano, ao contrário do homem que se debruça momentaneamente sobre uma obra de arte. Este se volta, orienta suas potências para a obra, a totalidade intensiva ali representada pode, então, transformar a forma como esse homem vê o mundo.

A obra de arte é, segundo o entendimento desta pesquisa, portadora de elementos que atuam sobre o homem transformando-o (ou não) de alguma forma. Parece possível dizer, com base na teoria lukacsiana da arte, que a obra de arte possui um caráter educativo. Aqui se está tratando da educação em sentido amplo. Não se trata da atividade educativa como um ato intencional e direcionado. Essa distinção é fundamental para diferenciar a perspectiva de Lukács das artes que ele chama de dirigidas (LUKÁCS, 2010a), a exemplo da arte proletária oficial da União Soviética durante o stalinismo.

Não se está afirmando aqui, como dito anteriormente, que arte e educação coincidam ou que a arte eduque como educa a educação. A falta de compreensão dialética da realidade pode levar a este equívoco. Lukács advertiu variadas vezes em suas obras, fazendo uso de assertiva de Croce que a arte educa enquanto arte não enquanto arte educativa, ou seja, o que possibilita à arte transformar o homem através do autoconhecimento do mundo é o que a particulariza como arte. Esta afirmação vai de encontro ao que tem fundamentado o ensino de arte na educação escolar desde meados de 1970, a arte-educação. Tal discussão não cabe no escopo deste texto, mas merece este breve comentário.

$\mathrm{Na}$ arte, a unidade inseparável do real entre essência e fenômeno é criada para que a essência apareça em todas as formas fenomênicas de modo que a essência se revele imediata e claramente no fenômeno. Esse é o apego ao real defendido por Lukács. O artista comprometido em refletir em sua obra a realidade humana como ela é, procurando dar conta da essência, precisa criar um mundo artístico no qual não haja falseamento, mas uma compreensão por parte do receptor da obra. Marx e Engels exaltam Balzac exatamente pelo fato do escritor francês respeitar a realidade em detrimento de suas próprias convicções 
pessoais. Leia-se trecho de Engels em carta a Margaret Harkness, 1888 (MARX; ENGELS, 2010, p. 68-69):

\begin{abstract}
Balzac - que considero um mestre do realismo maior que todos os Zola do passado, do presente e do futuro - desenvolve em sua Comédia Humana a mais extraordinária história realista da sociedade francesa, narrando, ano a ano e como se fora uma crônica, os costumes imperantes entre 1816 e 1848. Ele dá forma ao crescente movimento da burguesia que depois de 1815 se reestruturou na medida do possível, restabelecendo o estandarte da antiga política francesa.
\end{abstract}

E segue:

Claro que, por suas concepções políticas, Balzac era um legitimista. Sua grandiosa obra é uma permanente elegia acerca da irremediável decomposição da alta sociedade; suas simpatias estão com a classe condenada a desaparecer. Mas, ao mesmo tempo, a sua sátira nunca é tão aguda, nem sua ironia é mais amarga, como quando faz agir os homens que mais o atraem: os aristocratas.

Lukács (1966, p. 20) afirma que a necessidade da evidência imediata da essência no fenômeno se apresenta de maneira mais clara na literatura, pois, segundo ele, como a clarificação do princípio só acontece no final do enredo, seria artificial e equivocado se o caminho que leva ao desfecho não se apresentasse de modo evidente em cada etapa do entrecho. "Assim, pois, as determinações essenciais do mundo representado por uma obra de arte literária se revelam em uma sucessão e em uma gradação artísticas". (LUKÁCS, 1966, p. 20, tradução nossa).

O caráter educativo da literatura está acima representado. Há muitas mediações nesse processo que ainda precisam ser aprofundadas em estudos posteriores, mas parece razoável advogar esse papel para a literatura nos termos postos por Lukács. Partindo deste ponto nodal, faz-se fundamental pensar a práxis do professor de literatura. Ao tratar de ensino, a partir deste momento, leva-se em consideração que o lugar da educação formal nessa sociedade é a escola. Compreendendo com Saviani (1994) as duas dimensões da educação: em sentido amplo e em sentido restrito.

Entendendo, por um lado, não ser possível uma política de Estado para uma escola pública dos trabalhadores, com didática, currículo, diretrizes, parâmetros e políticas voltados aos interesses da classe trabalhadora, por outro, advogando a necessidade de se pensar, além de atividades educativas de caráter emancipador (TONET, 2013), uma didática que se fundamente na teoria revolucionária marxiana e sua tradição clássica. (SAVIANI, 2008). O debate em torno da posição dos dois teóricos citados aqui demonstra a pungência de se pensar no Que fazer? pela educação do trabalhador hoje.

O professor de literatura lida com a literatura como matéria escolar de duas maneiras principais. Como um conhecimento científico da história do desenvolvimento da literatura, das características do texto, dos escritores e das escolas literárias; este é priorizado pelo currículo e pelos instrumentos de avaliação internos e externos à escola. Por outro lado, o professor lida com uma obra de arte que exerce uma função social, como demonstrado até aqui; o texto literário como uma objetivação humana. Em meio a essas questões, o professor precisa fazer escolhas práticas para que seus estudantes adquiram, além do exigido pelo currículo, experiências com a literatura. 
Conciliar o trabalho docente do professor de literatura com essas duas necessidades parece ser o caminho de uma práxis de caráter emancipador, ou seja, de interesse dos trabalhadores. Proporcionar aos alunos, com ênfase na escola pública, os conhecimentos e habilidades necessários à fruição da obra literária que eleve sua consciência a outros patamares, enriquecendo sua compreensão da realidade, de si mesmo e dos homens, neste sentido, a educação proporcionada pela literatura se insere na educação em sentido amplo, ou seja, contribui para formação do homem como partícipe de um gênero.

Parece ser um ponto de partida escolher obras a serem lidas na integralidade com base na proximidade entre problemas vivenciados pelos estudantes e o enredo figurado na obra, como mecanismo de desenvolvimento do interesse dos alunos. Esse não pode ser, entretanto, um critério permanente, já que não há como afirmar que uma obra que trate de uma porção da realidade mais distante dos alunos não será compreendida. O importante é oferecer uma variedade de obras de qualidade estética e, em paralelo, desenvolver as habilidades para os estudantes entendê-las e muni-los dos conhecimentos históricos da literatura.

O processo de acompanhamento das leituras deve sobrepor avaliações quantitativas. A preocupação em checar se o aluno entendeu ou não determinados aspectos do texto lido não deve direcionar a atividade do professor, tendo em vista que não é possível garantir a eficácia pedagógico-social de determinada obra literária. Mesmo que as fichas de leitura tenham sido abolidas como metodologia de avaliação de leitura, ainda se está preso a métodos mecanicistas de avaliação, como provas e seminários. Deixar fruir a leitura pode ser bem mais proveitoso para o aluno. $\mathrm{O}$ efeito pode não ser o desejado pelo docente, mas a relação estabelecida entre leitor e livro é pessoal.

Há muito se tem falado em interdisciplinaridade nas discussões educacionais. $\mathrm{O}$ conceito já se tornou palavra de moda, mas efetivamente o ensino permanece fragmentado. Vale a pena ao professor de literatura compreender o caráter interdisciplinar do reflexo artístico, no sentido de que ele apresenta todas as mediações necessárias para aquela porção de realidade refletida. Ao compreender desta forma, atribui-se um conceito mais amplo de inter ou mesmo transdisciplinaridade, superando a mera relação entre as disciplinas, mas compreendendo a totalidade extensiva do real e a totalidade intensiva da obra.

\section{CONSIDERAÇÕES FINAIS}

Procurou-se apontar aqui uma série de discussões sobre o entendimento do papel da arte, da estética e da literatura com base na teoria marxiana e sua tradição, para defender que estes conhecimentos são fundamentais. Assim, o professor de literatura pode compreender a natureza do objeto com o qual trabalha e perceber de que maneira a literatura atua na formação de seus educandos. Dessa forma, poderá ampliar seu papel como educador desta área de conhecimento.

O pensamento de Lukács traz à tona a necessidade de pensar a arte como uma manifestação do ser genérico do homem, como uma objetivação posta na realidade por ele, superando as perspectivas anteriores que procuravam definir a arte como uma faculdade humana inata ou como manifestação de uma superioridade além do humano. Ao contrário, a arte é resultado das ações dos homens sobre a natureza e a sociedade. 
O marxismo é uma teoria que procura apreender o mundo na sua objetividade sem se debruçar sobre teorias transcendentes, determinando que o homem é consequência do que ele faz na história e de que a história é consequência de seus atos, numa relação dialética, mesmo que ele não tenham condições de determinar todas as possibilidades de suas ações para o futuro. O marxismo parte da realidade, da práxis social para entender o mundo.

Desta forma, a arte e a estética devem ser entendidas também como consequência da ação dos homens. A arte, a estética e todas as categorias que as formam surgiram em consequência do processo de humanização. Esse entendimento tem consequências para a teoria estética, pois a categoria beleza, por exemplo, não é uma idealização a priori, mas uma construção humana. Os elementos estão na natureza, o que os fazem belos não é a percepção do homem para identificar o que é belo, mas a construção do que é belo para o homem pelo próprio homem, num processo histórico. A estética marxista de Lukács, então, supera a contemplação como justificação para a estética e suas categorias.

A tarefa do professor de literatura ou mesmo de quaisquer áreas não é simples. Reduzir o acesso às objetivações humanas que auxiliam no processo de conhecimento e autoconhecimento do ser e do mundo, como a ciência e a arte, é próprio da sociedade capitalista e do seu aparato de produção e reprodução. Encontrar meios para burlá-lo é dever dos membros da classe trabalhadora, em especial de seus intelectuais orgânicos, nos termos de Antônio Gramsci. O professor consciente para a luta pela superação do capitalismo tem, então, a tarefa revolucionária de lutar pelos direitos educacionais dos trabalhadores, como o acesso à arte e à educação. Se inserir esse acesso na práxis do professor pode tornar a sala de aula num espaço de contradição e problematização, embora dentro dos limites e possibilidades reais da escola atual.

O diálogo entre o marxismo, a estética e a educação é necessário à contemporaneidade para que se possa recolocar a práxis no centro da produção de conhecimento em todas as áreas. A arte como expressão da subjetividade humana perante o mundo tem papel fundamental nesse processo, pois cumpre a função de refletir a realidade circundante e levar ao homem um conhecimento dessa mesma realidade. A relação entre estética e marxismo torna possível um diálogo entre conhecimento histórico e conhecimento estético, assim, medeia o conhecimento da realidade para o homem com o fito de transformála revolucionariamente.

\section{REFERÊNCIAS}

COSTA, Frederico Jorge Ferreira. Ideologia e educação na perspectiva da ontologia marxiana. 2007. Tese (Doutorado em Educação) - Universidade Federal do Ceará, Fortaleza, 2007.

COUTINHO, Carlos Nelson; PAULO NETTO, José. Apresentação. In: LUKÁCS, György. Arte e sociedade: escritos estéticos 1932-1967. Organização e tradução de Carlos Nelson Coutinho e José Paulo Netto. 2. ed. Rio de Janeiro: Ed. da UFRJ, 2011. p. 8-20.

INFRANCA, Antonino. Estudio preliminar. In: VEDDA, Miguel. La sugestión de lo concreto: estudios sobre teoria literaria marxiana. Buenos Aires: Goria, 2006. 
LIFSCHITZ, Mikhail. Prólogo. In: MARX, Karl; ENGELS, Friedrich. Cultura, arte e literatura: textos escolhidos. Tradução de José Paulo Netto e Miguel Makoto Cavalcanti Yoshida. São Paulo: Expressão Popular, 2010.

LUKÁCS, Georg. A estética de Hegel. In: Arte e sociedade: escritos estéticos 1932-1967. Organização e tradução de Carlos Nelson Coutinho e José Paulo Netto. 2. ed. Rio de Janeiro: Editora UFRJ, 2011. p. 43-86.

LUKÁCS, Georg. Arte livre ou arte dirigida? In: Marxismo e teoria da literatura. 2. ed. Tradução de Carlos Nelson Coutinho. São Paulo: Expressão Popular, 2010a. p. 267-285.

LUKÁCS, Georg. Arte y verdad objetiva. In: . Problemas del Realismo. Traducción de Carlos Gerhard. México D.C; Buenos Aires: Fondo de Cultura Económica, 1966. p. 11-54.

LUKÁCS, Georg. Estetica 1: la peculiaridad de lo estetico. Traducción de Manuel Sacristán. Barcelona: Ediciones Grijaldo, 1982.

LUKÁCS, Georg. Introdução aos escritos estéticos de Marx e Engels. In: MARX, Karl; ENGELS, Friedrich. Cultura, arte e literatura: textos escolhidos. Tradução de José Paulo Netto e Miguel Makoto Cavalcanti Yoshida. São Paulo: Expressão Popular, 2010b. p. 1138 .

MARX, Karl; ENGELS, Friedrich. Cultura, arte e literatura: textos escolhidos.

Tradução de José Paulo Netto e Miguel Makoto Cavalcanti Yoshida. São Paulo: Expressão Popular, 2010. p. 11-38.

MARX, Karl; ENGELS, Friedrich. Teses sobre Feuerbach. In: A ideologia alemã: crítica da novíssima filosofia alemã em seus representantes Feuerbach, B. Bauer e Stiner; e do socialismo alemão em seus diferentes profetas, 1845-1846. Tradução de Marcelo Backes. Rio de Janeiro: Civilização Brasileira, 2007.

MARX, Karl. Manuscritos econômico-fillosóficos. Tradução de Jesus Ranieri. São Paulo: Boitempo, 2010.

PAULO NETTO, José. Lukács: tempo e modo. In: ed. São Paulo: Ática, 1992.

. Georg Lukács: sociologia. 2.

SAVIANI, Demerval. O trabalho como princípio educativo frente às novas tecnologias. In: FERRETI, Celso João (Org.). Novas tecnologias, trabalho e educação: um debate multidisciplinar. Petrópolis: Vozes, 1994.

SAVIANI, Demerval. Pedagogia Histórico-Crítica: primeiras aproximações. 10. ed. Campinas: Autores Associados, 2008. (Educação Contemporânea).

TERTULIAN, Nicolas. Georg Lukács: etapas de seu pensamento estético. Tradução Renira Lisboa de Moura Lima. São Paulo: Ed. da UNESP, 2008. 
TONET, Ivo. Educação, cidadania e emancipação humana. 2. ed. Maceió: Ed. da EDUFAL, 2013.

Notas

\footnotetext{
${ }^{1}$ Doutoranda pelo Programa de Pós-graduação em Educação da Universidade Estadual do Ceará (UECE), professora da rede estadual de ensino do Ceará (SEDUC/CE).

${ }^{2}$ Doutor pelo Programa de Pós-graduação em Educação Brasileira pela Universidade Federal do Ceará (UFC), Professor da Universidade Estadual do Ceará (UECE).

${ }^{3}$ Sobre as categorias desantropomorfização e antropomorfização: a primeira parte da realidade objetiva para a consciência, levando seus conteúdos e suas categorias; a segunda parte de uma projeção de dentro para fora: do homem para a natureza.
}

Submetido em: 30/04/2016

Aprovado em: 04/09/2017 